\title{
Reversed-phase liquid chromatography coupled on-line to estrogen receptor bioaffinity detection based on fluorescence polarization
}

\author{
Jelle Reinen • Jeroen Kool • Nico P. E. Vermeulen
}

Received: 25 September 2007 /Revised: 1 January 2008 / Accepted: 7 January 2008 /Published online: 31 January 2008

(C) The Author(s) 2008

\begin{abstract}
We describe the development and validation of a high-resolution screening (HRS) platform which couples gradient reversed-phase high-performance liquid chromatography (RP-HPLC) on-line to estrogen receptor $\alpha(\mathrm{ER} \alpha)$ affinity detection using fluorescence polarization (FP). FP, which allows detection at high wavelengths, limits the occurrence of interference from the autofluorescence of test compounds in the bioassay. A fluorescein-labeled estradiol derivative (E2-F) was synthesized and a binding assay was optimized in platereader format. After subsequent optimization in flow-injection analysis (FIA) mode, the optimized parameters were translated to the on-line HRS bioassay. Proof of principle was demonstrated by separating a mixture of five compounds known to be estrogenic (17 $\beta$-estradiol, $17 \alpha$-ethinylestradiol and the phytoestrogens coumestrol, coumarol and zearalenone), followed by post-column bioaffinity screening of the individual affinities for ER $\alpha$. Using the HRS-based FP setup, we were able to screen affinities of off-line-generated metabolites of zearalenone for ER $\alpha$. It is concluded that the on-line FP-based bioassay can be used to screen for the affinity of compounds without the disturbing occurrence of autofluorescence.
\end{abstract}

J. Reinen · J. Kool • N. P. E. Vermeulen $(\bowtie)$

Department of Chemistry and Pharmaceutical Sciences, LACDR-Division of Molecular Toxicology, Vrije Universiteit, De Boelelaan 1083,

1081 HV Amsterdam, The Netherlands

e-mail: npe.vermeulen@few.vu.nl

J. Kool

Biomolecular Analysis, Department of Chemistry and

Pharmaceutical Sciences, Vrije Universiteit,

De Boelelaan 1083

1081 HV Amsterdam, The Netherlands
Keywords Fluorescence polarization · High-resolution screening (HRS) · Estrogen receptor $\alpha$. Phytoestrogens . On-line bioaffinity assay $\cdot$ Receptor affinity detection (RAD)

\section{Introduction}

In recent years, the presence of endocrine-disrupting compounds (EDCs) in the environment has become a major issue of concern in view of their effects on both human health and ecosystem integrity. The classes of substances that possess estrogenic activities include diverse manmade and natural chemicals (e.g., pesticides, plasticizers, polychlorinated biphenyls, phytoestrogens, natural hormones) and pharmaceuticals (e.g., ethinylestradiol, tamoxifen) $[1,2]$. EDCs can interfere with the endocrine system by binding to the estrogen receptors $\alpha(E R \alpha)$ or $\beta(E R \beta)$ and mimicking the action of the naturally produced hormone estrogen or blocking the receptor for this hormone in target cells, thereby preventing its action [3]. Therefore, it is important to screen compounds and compound mixtures for their ability to bind to one of these receptors. Alternatively, the task of screening for compounds containing estrogenic and antiestrogenic properties is also very important from medical and pharmaceutical points of view [4].

Several biodetection methodologies have meanwhile been developed to determine the bioaffinities of ligands towards $\mathrm{ER} \alpha$. These assays include relatively cumbersome radioligand binding assays [5], fluorescence enhancement based assays [6] and fluorescence polarization (FP) based binding assays [7]. A major drawback of these assays is that, in the presence of cross-reactive compounds, the response provided by the bioassay reflects the sum of the concentrations of all individual compounds and their affinities for the ER $\alpha$. Moreover, matrix components, which are sometimes present in far higher concentrations than the analyte(s), interfere with 
the binding assay signals, thereby leading to false-positive or false-negative results [8]. Therefore, none of these methods can be applied for the identification of individual ER $\alpha$ binding ligands in mixtures of compounds, as is the case with natural compound extracts, biological samples containing different EDCs, and drug metabolite mixtures.

However, the introduction of the on-line high-resolution screening (HRS) technology enabled the screening of individual compounds in mixtures by coupling a separation technology, usually gradient HPLC, to post-column biochemical detection assays on-line [9-14]. Oosterkamp et al. [10] developed a HRS system to screen mixtures for compounds with an affinity for ER $\alpha$. A similar setup has been used to screen natural plant product extracts for ER $\alpha$ and ER $\beta$ binding activity [15] and to identify and screen cytochrome P450-derived metabolites of tamoxifen with $\mathrm{ER} \alpha$ affinity $[2,16]$. The reported HRS ER $\alpha$ bioaffinity assays are based on the increase of the fluorescent signal of the tracer compound coumestrol upon binding to the ER $\alpha$ ligand binding domain (LBD). When the tracer is displaced by a compound with ER $\alpha$ affinity that elutes from the HPLC column, it is seen as a negative peak in the baseline of the ER $\alpha$ bioassay. Coumestrol, the fluorescent probe, has short excitation $(340 \mathrm{~nm})$ and emission $(410 \mathrm{~nm})$ wavelengths when bound to the ER $\alpha$ LBD [6]. Since there are many potentially interfering fluorescent compounds that can be excited at $300-350 \mathrm{~nm}$ and emit at $360-430 \mathrm{~nm}$ in biomatrices, coumestrol is not appropriate for the precise and selective detection of EDCs in biosamples containing phytoestrogens such as flavonoids, coumestans or lignans. One solution to this problem is to use another tracer compound, thus making it possible to monitor the bioassay signal at higher excitation and emission wavelengths. However, no tracer compounds are currently available which also display the necessary fluorescence enhancement upon binding to the $\mathrm{ER} \alpha$, thus making it impossible to use them in a HRS ER $\alpha$ setup. Another option is fluorescence polarization (FP) detection. FP is based upon the principle that interaction of a receptor with a fluorophore-containing ligand increases the effective size of the fluorophore through the formation of a receptor ligand complex. The increase in effective size reduces the rate of fluorophore rotation and increases the polarization over that of the unbound fluorophore [7]. FP instruments measure the rate of fluorophore rotation in solution rather than fluorescence intensity [17]. The polarization value is independent of the fluorophore concentration and intensity and has the advantage that it is minimally affected by autofluorescence, solution opacity or color, and is more tolerant to fluorescence quenching and light scattering [18].

The objective of the present study was to develop and evaluate the use of FP detection in combination with the online HRS technology to provide information about the ER $\alpha$ affinities of individual compounds in complex mixtures. The assay is based on competition for the ER $\alpha$ LBD between eluting compounds and a fluorescein-labeled estradiol derivative (E2-F), which was synthesized based on tracer structures described by Parker et al. [7] and Ohno et al. [19] for off-line FP-based ER assays. After synthesis of the tracer E2-F, the ER $\alpha$ binding assay was first optimized in FP platereader format and subsequently transferred to flow-injection analysis (FIA) mode with FP detection by using an on-line FP detector cell, which was recently constructed by Kool et al. [20] to measure GPCR-mediated modulation of cAMP production. Finally, after optimization of the assay in FIA mode, the on-line FP detection system was coupled to a gradient HPLC system. In this so-called HRS setup we separated mixtures of known estrogenic compounds-e.g., $17 \beta$-estradiol, $17 \alpha$-ethinylestradiol and the phytoestrogens coumestrol, coumarol and zearalenone-and screened the individual compounds for $\mathrm{ER} \alpha$ affinities. We also showed that this HRS ER $\alpha$-FP system was suitable for screening offline-generated cytochrome P450 (Cyt P450) metabolites of zearalenone for $\mathrm{ER} \alpha$ affinity. We conclude that we were able to incorporate an on-line FP detector cell into a HRS system to screen for the ER $\alpha$ affinities of individual compounds in complex mixtures without incurring interference from the autofluorescence of the compounds.

\section{Materials and methods}

\section{Materials}

Tween 20,17 $\beta$-estradiol (E2), estrone (E1), 17 $\alpha$-ethinyl estradiol (EE2), diethylstilbestrol (DES), estriol, zearalenone, fluorescein-5-isothiocyanate (5-FITC) and coumestrol were obtained from Sigma-Aldrich (Zwijndrecht, The Netherlands). ELISA blocking reagent was purchased from Roche (Mannheim, Germany). Dry THF was freshly distilled from $\mathrm{LiAlH}_{4}$. All other chemicals were of analytical grade and obtained from standard suppliers.

\section{Synthesis}

Fluorescein-labeled estradiol derivative (E2-F) The fluorescein-labeled estradiol derivative (E2-F) was synthesized in analogy to methods described previously [7, 19] from estrone as the starting material (Fig. 1). To a solution of estrone $(1,700 \mathrm{mg}, 2.59 \mathrm{mmol})$ in dry DMF (3 mL), imidazole $(250 \mathrm{mg})$ was added. Subsequently, tert-butyl dimethylsilyl chloride (tBDSC) dissolved in dry THF $(2 \mathrm{~mL})$ was slowly added and the reaction mixture was stirred at room temperature for $3 \mathrm{~h}$. The resulting cloudy white mixture was extracted with ethyl acetate (EtOAc). The organic extract was washed with water once, with brine 


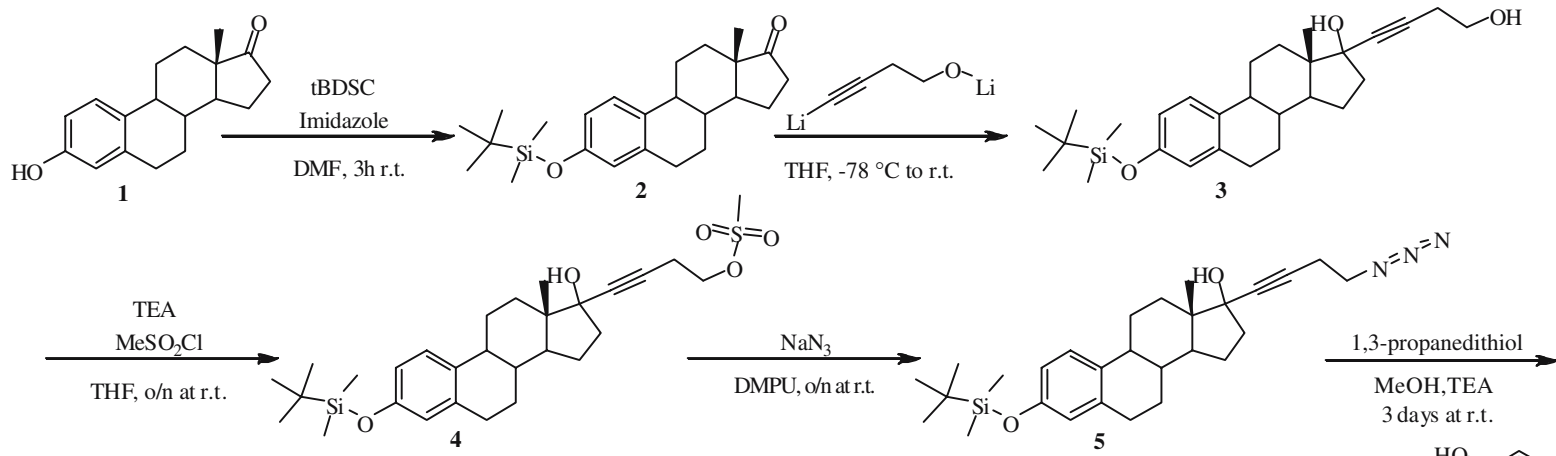

$\mathrm{OH}$

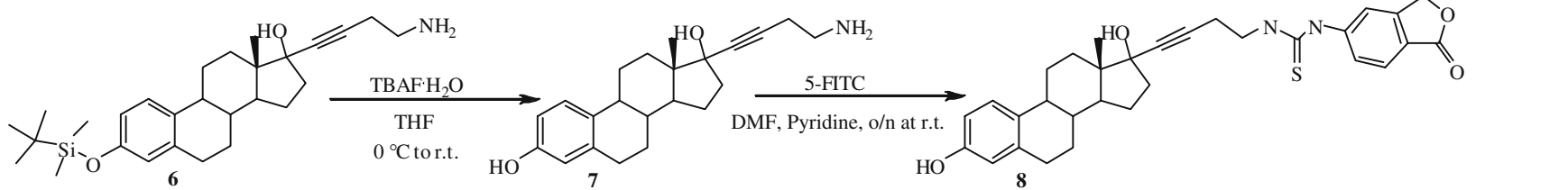

Fig. 1 Synthesis of a fluorescein-labeled estradiol (E2-F) derivative (for abbreviations, see "Experimental" section)

twice and then with water once again. The organic extract was dried over $\mathrm{MgSO}_{4}$, filtered, and concentrated by rotary evaporation at $45{ }^{\circ} \mathrm{C}$. Recrystallization was performed using a mixture of $15 \mathrm{~mL} \mathrm{MeOH}$ and $5 \mathrm{~mL}$ DCM to afford $2(667.2 \mathrm{mg}, 67 \%)$. Under an atmosphere of dry nitrogen, 3-butyn-1-ol (1.35 g) was dissolved in dry THF $(27 \mathrm{~mL})$ and cooled to $-78{ }^{\circ} \mathrm{C}$. $n$-Butyllithium (BuLi) in hexane $(16.9 \mathrm{~mL}, 0.027 \mathrm{~mol})$ was added dropwise at $-78{ }^{\circ} \mathrm{C}$. Compound 2 (3.60 g, $9.36 \mathrm{mmol})$ dissolved in dry THF $(25 \mathrm{~mL})$ was carefully added dropwise at $-78^{\circ} \mathrm{C}$ and the solution was allowed to warm to room temperature and was thereafter stirred at $40{ }^{\circ} \mathrm{C}$ for an additional $60 \mathrm{~min}$. The remaining BuLi was neutralized by carefully adding $5 \mathrm{~mL}$ EtOAc/MeOH (1:1). Extraction was performed with EtOAc, as described above. The crude product was purified by column chromatography on silica gel $(10 \%$ EtOAc in hexane) to afford $\mathbf{3}(1.62 \mathrm{~g}, 38 \%)$. To a solution of $\mathbf{3}(1.6 \mathrm{~g}$, $3.52 \mathrm{mmol})$ dissolved in dry THF $(25 \mathrm{~mL})$ was added triethylamine (TEA, $718 \mu \mathrm{L}$ ) followed by $\mathrm{MeSO}_{2} \mathrm{Cl}$ $(395 \mu \mathrm{L}, 5.1 \mathrm{mmol})$ while stirring at $0{ }^{\circ} \mathrm{C}$. Afterwards the solution was allowed to warm to room temperature. After $10 \mathrm{~h}$ the reaction mixture was extracted with DCM. The organic extract was treated as described above and concentrated by rotary evaporation to afford $4(1.80 \mathrm{~g}$, $96 \%)$. Under an atmosphere of dry nitrogen, $\mathrm{NaN}_{3}(8.0 \mathrm{~g})$ was added to a solution of $\mathbf{4}(1.80 \mathrm{~g}, 3.38 \mathrm{mmol})$ dissolved in dry DMPU $(25 \mathrm{~mL})$ while stirring rapidly. After stirring the solution for three days, the resulting reaction mixture was extracted with EtOAc as described above to afford $\mathbf{5}$ $(1.36 \mathrm{~g}, 84 \%)$. To a solution of $5(1.36 \mathrm{~g}, 2.83 \mathrm{mmol})$ in $\mathrm{MeOH}(70 \mathrm{~mL})$ and TEA $(16 \mathrm{~mL}), 1,3$-propane dithiol $(12 \mathrm{~mL})$ was added. The solution was stirred $\mathrm{o} / \mathrm{n}$ at room temperature and was concentrated by rotary evaporation. The concentrated solution dissolved in $100 \mathrm{~mL}$ hexane was purified by column chromatography on silica gel. Elution of the purified product $6(1.08 \mathrm{~g}, 84 \%)$ was performed using EtOAc/MeOH (1:1). To remove the protective tert-butyl dimethylsilyl group, TBAF. $\mathrm{H}_{2} \mathrm{O}(300 \mathrm{mg})$ was added to a solution of 6 (258 mg, $0.57 \mathrm{mmol})$ dissolved in dry THF $(4 \mathrm{~mL})$ at $0{ }^{\circ} \mathrm{C}$. After stirring for $1 \mathrm{~h}$ and allowing the solution to warm to room temperature, the crude product was extracted with DCM. The product was purified with Flash Master chromatography with an EtOAc/MeOH gradient to afford 7 (176 $\mathrm{mg}, 91 \%)$. Fluorescein-5isothiocyanate (5-FITC, $7 \mathrm{mg}, 17.8 \mu \mathrm{mol})$ was added to a solution of $7(5 \mathrm{mg}, 14.7 \mu \mathrm{mol})$ dissolved in dry DMF $(500 \mu \mathrm{L})$ and dry pyridine $(25 \mu \mathrm{L})$. The solution was stirred $\mathrm{o} / \mathrm{n}$ in the dark at room temperature. The crude product was extracted with DCM and purified first with Flash Master chromatography (silicagel-based; EtOAC/MeOH gradient) and then with preparative $\mathrm{C}_{18}$ HPLC to afford 8 (E2-F, $8.02 \mathrm{mg}, 75 \%) .{ }^{1} \mathrm{H}$ NMR $\left(400.13 \mathrm{MHz}, \mathrm{CD}_{3} \mathrm{OD}\right): \delta 8.04$ $(1 \mathrm{H}, \mathrm{d}, J=1.9 \mathrm{~Hz}), 7.70(1 \mathrm{H}, \mathrm{dd}, J=8.2,1.9 \mathrm{~Hz}), 7.10$ $(1 \mathrm{H}, \mathrm{d}, J=8.2 \mathrm{~Hz}), 7.01(1 \mathrm{H}, \mathrm{d}, J=8.5 \mathrm{~Hz}), 6.89(1 \mathrm{H}, \mathrm{d}$, $J=8.9 \mathrm{~Hz}), 6.88(1 \mathrm{H}, \mathrm{d}, J=8.9 \mathrm{~Hz}), 6.66(2 \mathrm{H}, \mathrm{d}, J=$ $2.3 \mathrm{~Hz}), 6.58(2 \mathrm{H}, \mathrm{dd}, J=8.9,1.9 \mathrm{~Hz}), 6.47(1 \mathrm{H}, \mathrm{dd}, J=$ $8.5,2.6 \mathrm{~Hz}), 6.42(1 \mathrm{H}, \mathrm{d}, J=2.6 \mathrm{~Hz}), 3.80(2 \mathrm{H}, \mathrm{t}$, $J=6.6 \mathrm{~Hz}), 2.70(1 \mathrm{H}, \mathrm{d}, J=1.9 \mathrm{~Hz}), 2.65(2 \mathrm{H}, \mathrm{t}, J=$ $6.6 \mathrm{~Hz}), 2.1-2.3(3 \mathrm{H}, \mathrm{m}), 1.9-2.0(2 \mathrm{H}, \mathrm{m}), 1.65-1.85$ $(4 \mathrm{H}, \mathrm{m}), 1.25-1.50(5 \mathrm{H}, \mathrm{m}), 0.85(3 \mathrm{H}, \mathrm{s})$. ESI-MS: $\mathrm{m} / \mathrm{z}$ $729(\mathrm{M}+\mathrm{H})^{+}$.

7-Hydroxy-3-p-hydroxyphenylcoumarine (coumarol) The synthesis of coumarol was analogous to the synthesis of benzene-hydroxylated-3-aryl-coumarins described by BuuHoi et al. [21]. Briefly, 2,4-dimethoxybenzaldehyde was reacted with $p$-methoxyphenyl-acetonitrile to form $\alpha$ - $p$ methoxyphenyl- $\beta$-(2,4-dimethoxyphenyl)-acrylonitrile. The 
formed product formed was demethylated using pyridine hydrochloride to form the final product coumarol. ${ }^{1} \mathrm{H}$ NMR (400.13 MHz, DMSO-d $\left.{ }_{6}\right): \delta 10.57(1 \mathrm{H}, \mathrm{s}), 9.68(1 \mathrm{H}, \mathrm{s})$, $8.00(1 \mathrm{H}, \mathrm{s}), 7.56(1 \mathrm{H}, \mathrm{d}, J=8.6 \mathrm{~Hz}), 7.53(2 \mathrm{H}, \mathrm{d}, J=$ $8.7 \mathrm{~Hz}), 6.81(2 \mathrm{H}, \mathrm{d}, J=8.7 \mathrm{~Hz}), 6.80(1 \mathrm{H}, \mathrm{dd}, J=10.8$, $2.7 \mathrm{~Hz}), 6.73(1 \mathrm{H}, \mathrm{d}, J=2.2 \mathrm{~Hz})$. ESI-MS: $m / z 255(\mathrm{M}+\mathrm{H})^{+}$.

\section{Biomaterials}

Microsomes Rat liver microsomes were prepared from phenobarbital (PB)-induced rat liver, as described previously by Roosenboom et al. [22].

Estrogen receptor $\alpha$ The ER $\alpha$ ligand binding domain (LBD) was expressed in Escherichia coli according to the method of Eiler et al. [23], but without estradiol in the medium. The concentration of ER $\alpha$ LBD $(250 \mathrm{nM})$ was measured by determining the $B_{\max }$ value (by titration with radiolabeled estradiol) [24]. The $B_{\max }$ value was measured as the maximum amount of ligand binding extrapolated to a very high concentration of ligand.

\section{Microsomal incubations}

Microsomal PB-induced rat liver incubations were carried out in a total volume of $500 \mu \mathrm{L}$. The reaction mixture consisted of $2.5 \mathrm{mM} \mathrm{MgCl}_{2}$ in $100 \mathrm{mM}$ potassium phosphate buffer $(\mathrm{pH}$ 7.4), $100 \mu \mathrm{M}$ zearalenone and $2.6 \mathrm{mg} / \mathrm{mL}$ rat liver microsomes. The reactions were initiated by the addition of a NADPH regenerating system, resulting in final concentrations of $0.1 \mathrm{mM}$ NADPH, $0.3 \mathrm{mM}$ glucose-6-phosphate, and $0.4 \mathrm{U} / \mathrm{mL}$ glucose-6-phosphate dehydrogenase. Incubation was carried out at $37{ }^{\circ} \mathrm{C}$ for $120 \mathrm{~min}$ and the reaction was terminated by the addition of $50 \mu \mathrm{L} 10 \% \mathrm{HClO}_{4}$. Following centrifugation at $14,000 \mathrm{rpm}$ for $10 \mathrm{~min}, 450 \mu \mathrm{L}$ of supernatant was applied to a strata_X $33 \mu \mathrm{m}$ Polymeric Sorbent $200 \mathrm{mg} / 3 \mathrm{~mL}$ (Phenomenex, Amstelveen, The Netherlands) column for SPE sample preparation. Before sample application the column was conditioned with $2 \mathrm{~mL} \mathrm{MeOH}$ and subsequently equilibrated with $2 \mathrm{~mL}_{2} \mathrm{O}$. The sample was washed with $2 \mathrm{~mL} 5 \%(\mathrm{v} / \mathrm{v})$ of aqueous methanol and elution was performed using $2 \mathrm{~mL} 50 \%(\mathrm{v} / \mathrm{v})$ of $\mathrm{MeOH}$ in $\mathrm{ACN}$. After evaporation, the residues were dissolved in $1 \mathrm{~mL} 40 \%$ $(\mathrm{v} / \mathrm{v})$ of aqueous methanol.

Instrumentation

A NOVOstar ${ }^{+}$microplate fluorometer from BMG LABTECH GmbH (Offenburg, Germany) was used for the FP-based microplate reader assay. The excitation wavelength was set at $485 \mathrm{~nm}$, the emission wavelength at $520 \mathrm{~nm}$. Black-bottomed
PP-96-well microtiter plates from Greiner Bio-one (Alphen a/d Rijn, The Netherlands) were used for all microplate reader experiments.

The setup we used was adapted from the homogeneous coumestrol-based ER $\alpha$ affinity detection system described by Kool et al. [2]. For the on-line FP assay, two Knauer K-500 HPLC pumps (Berlin, Germany) were used to control the $120-\mathrm{mL}$ superloops, made in-house, containing receptor $(\mathrm{ER} \alpha)$ and tracer ligand (E2-F), respectively, and one Knauer K-500 HPLC pump was used to deliver the injected samples. The ER $\alpha$ and E2-F solutions were prepared in sodium phosphate buffer $(10 \mathrm{mM}$; pH 7.4$)$ containing $150 \mathrm{mM} \mathrm{NaCl}$ and $0.4 \mathrm{mg} / \mathrm{mL}$ ELISA blocking reagent. Both superloops were kept on ice. Flow restrictors were inserted between the pumps and the superloops to ensure proper operation of the pumps at low flow rates. The flow restrictors consisted of natural PEEK tubing and resulted in back pressures of approximately 50 bar. The pressure limits of the pumps were set 20 bar higher than the working pressure, and VICI Jour backpressure regulators (Schenkon, Switzerland) were inserted after the superloops to prevent damage from possible clogging of the system. A Gilson 234 autoinjector (Villiers-le-Bel, France) equipped with a Rheodyne (Bensheim, Germany) six-port injection valve (different injection loops) was used to inject samples. To maintain the reaction coils at a constant temperature, a Shimadzu CTO10AC column oven (Duisburg, Germany) was integrated into the system. An Agilent 1100 (Waldbronn, Germany) series fluorescence detector $\left(\lambda_{\mathrm{ex}} 498 \mathrm{~nm} ; \lambda_{\mathrm{em}} 522 \mathrm{~nm}\right)$ was used to monitor fluorescence polarization, as described by Kool et al. [20]. Briefly, the standard $8 \mu \mathrm{L}$ FLD cell was modified with parallel-placed (both mounted in the detector cell) fluorescence polarization filters from Melles Griot (Didam, The Netherlands). One filter (12.5 mm visible pol. 350 $650 \mathrm{~nm}$ 03FPG019) was placed in the pathway of the excitation beam and one (Mount. Sheet Pol. 20.D- 16.9CA 03FPG001) in the pathway of the emission beam. All hardware was integrated into one HRS system by Kiadis B.V. (Groningen, the Netherlands), and was controlled by software developed by Kiadis B.V.

Coumestrol-based microplate reader assay of ER $\alpha$ affinity

The microplate reader assay for determining ER $\alpha$ binding based on the competition between fluorescent coumestrol and estrogenic compounds previously described by Gurer-Orhan et al. [6] was used to plot a competitive binding curve for E2-F.

FP-based microplate reader assay of ER $\alpha$ affinity

The microplate reader assay was used to optimize the FP $\mathrm{ER} \alpha$ receptor affinity detection (RAD) system in FIA and HPLC modes. This assay is based on the competition 
between estrogenic compounds and the newly synthesized fluorescein-labeled estradiol derivative (E2-F) for binding to the ER $\alpha$ LBD. Displacement of E2-F was measured as the decrease in fluorescence polarization intensity. Different concentrations of E2-F tracer were tested first. Since Tween 20, a detergent also used by Kool et al. in their coumestrolbased HRS ER $\alpha$ assay [2], can improve the resolution of the assay in HRS mode, and since organic modifiers are necessary for the optimal performance of the gradient HPLC system, the next step in the optimization process was to vary these parameters. The experiments were carried out at $24{ }^{\circ} \mathrm{C}$ with well volumes of $250 \mu \mathrm{L}$ binding buffer [potassium phosphate buffer $(10 \mathrm{mM}$; $\mathrm{pH}$ 7.4) containing $0.4 \mathrm{mg} / \mathrm{ml}$ ELISA blocking reagent]. The ER $\alpha$ LBD was introduced into the binding assay buffer at a final concentration of $1.64 \mathrm{nM}$. The E2-F stock solution was prepared in DMSO and dilutions were made in binding buffer. Concentrations ranging from $0.42 \mathrm{nM}$ to $3.31 \mu \mathrm{M}$ were investigated for E2-F optimization. For the experiments to investigate the detergent and organic modifier effects, the final concentration of E2-F in the assay was $83.3 \mathrm{nM}$. Aliquots of $25 \mu \mathrm{L}$ of organic modifier or detergent at various concentrations were pipetted into a 96-well plate that already contained either $75 \mu \mathrm{L}$ binding buffer (equal to $0 \%$ displacement) or $75 \mu \mathrm{L} 33.3 \mu \mathrm{M}$ E2 in binding buffer (equal to $100 \%$ displacement). The 96 -well plate was gently but thoroughly mixed after pipetting $75 \mu \mathrm{L}$ E2-F into each well. Finally, $75 \mu \mathrm{L}$ of the ER $\alpha$ LBD was pipetted into the wells. After an incubation time of $60 \mathrm{~min}$ at room temperature, the fluorescence polarization (FP) was recorded at $485 \mathrm{~nm}$ excitation and $520 \mathrm{~nm}$ emission. All experiments were performed in quadruplicate. The difference in FP $(\Delta \mathrm{FP})$ was calculated by subtracting the FP value found at $100 \%$ displacement from the FP value found when no E2 was present under different conditions.

FP-based ER $\alpha$ receptor affinity detection (RAD) in flow-injection analysis (FIA) mode

A schematic overview of the RAD system in FIA mode is depicted in Fig. 2. In this system the flow from a superloop containing ER $\alpha$ LBD is continuously mixed with flow from a superloop containing E2-F. Compound samples $(10 \mu \mathrm{L})$ are introduced into the system by flow injection into a carrier solution $(100 \mu \mathrm{L} / \mathrm{min})$. During optimization, the carrier solution was water. Injected compounds and $\mathrm{ER} \alpha$, added to the carrier stream via an inverted Y-type mixing union at a flow rate of $100 \mu \mathrm{L} / \mathrm{min}$, were allowed to bind in a Tefzel reaction coil $(25 \mu \mathrm{L})$. This mixture was combined with the flow of the E2-F solution of $100 \mu \mathrm{L} / \mathrm{min}$. The final equilibrium between $\mathrm{ER} \alpha$, compound, and E2-F was established in a knitted $0.5 \mathrm{~mm}$ i.d. PTFE reaction coil $(250 \mu \mathrm{L})$. The temperatures of both reaction coils were maintained constant at $37{ }^{\circ} \mathrm{C}$. Fluorescence polarization (FP) detection took place directly after the second reaction coil. When the binding of E2-F is decreased due to competition from an eluting ER $\alpha$ ligand, depolarization occurs. This decrease in fluorescence polarization is a measure of the affinity of the ligand towards $\mathrm{ER} \alpha$.

FP-based ER $\alpha$ receptor affinity detection coupled on-line to gradient HPLC

Coupling of the homogeneous ER $\alpha$ FP RAD assay to HPLC was performed in a similar way to that described

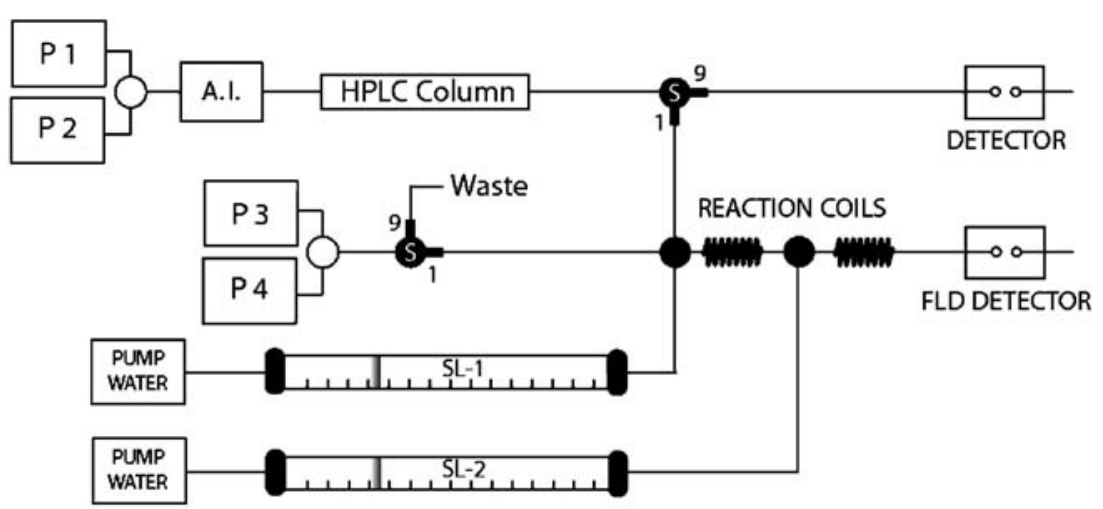

Fig. 2 Schematic overview of the ER $\alpha$ fluorescence polarization receptor affinity detection (RAD) system in high-resolution screening (HRS) mode. Samples are injected with an autoinjector (A.I.) and are separated using a gradient reversed-phase high-performance liquid chromatography (HPLC) system controlled by P1 and P2, HPLC gradient pumps. After the column the flow is split by a flow spitter, $S$ (split ratio 1:9). HPLC elution is monitored by UV or fluorescence detection. A makeup gradient, controlled by makeup gradient pumps $\mathrm{P} 3$ and $\mathrm{P} 4$, is introduced and eluting compounds are mixed in the first reaction coil with ER $\alpha$ delivered by superloop-1 (SL-1). In the second reaction coil, the probe ligand $\mathrm{E} 2-\mathrm{F}$ is added to the mix by superloop2 (SL-2). ER $\alpha$ affinity detection is performed using a fluorescence detector (FLD). In FIA mode the samples are delivered directly by a carrier solution into the bioassay 
recently by Kool et al. [14] for a Cyt P450 affinity assay. When operating the ER $\alpha$ FP RAD system in HPLC mode (Fig. 2), two pumps were used to control the HPLC gradient and, directly after the HPLC column, the HPLC eluent was split into a 1:9 ratio where nine-tenths of the flow was directed to either an UV (Agilent 1100 series) or fluorescence detector (Agilent 1100 series). The choice of detector depended on the compounds to be analyzed. To compensate for increasing the organic modifier concentrations before the delivery of the HPLC eluent to the ER $\alpha$ FP RAD system, two pumps were used to supply a makeup flow consisting of an opposite $\mathrm{H}_{2} \mathrm{O} / \mathrm{MeOH}$ gradient compared with the HPLC gradient in order to keep the $\mathrm{MeOH}$ concentration in the assay constant at $10 \%$. One-tenth of the total makeup flow was combined with one-tenth of the HPLC eluent and this flow was directed to the ER $\alpha$ FP RAD at $160 \mu \mathrm{l} / \mathrm{min}$. The remaining part of the flow in the $\mathrm{ER} \alpha$ FP RAD was the same as described above, with the exception that the HPLC flow combined with the makeup flow replaced the carrier solution flow.

For HPLC analysis, test compounds were dissolved in 50\% $\mathrm{MeOH}$ in water. For coumestrol, a linear gradient from $75 \%$ $\mathrm{MeOH}$ to $99 \% \mathrm{MeOH}$ in $7.5 \mathrm{~min}$, constant for $47.5 \mathrm{~min}$, and back to $75 \% \mathrm{MeOH}$ in $1 \mathrm{~min}$ was applied. The total flow of the HPLC pumps was $162 \mu \mathrm{L} / \mathrm{min}$ and detection took place by measuring UV at $254 \mathrm{~nm}$. For the mixture containing estriol, coumestrol, coumarol, E2 and zearalenone, constant elution at $55 \% \mathrm{MeOH}$ for $40 \mathrm{~min}$, followed by a linear gradient from $55 \% \mathrm{MeOH}$ to $70 \% \mathrm{MeOH}$ in $50 \mathrm{~min}$, constant for $50 \mathrm{~min}$, and back to $55 \% \mathrm{MeOH}$ in $1 \mathrm{~min}$ was applied. The total flow rate of the HPLC pumps was $229 \mu \mathrm{L} / \mathrm{min}$ and detection took place using UV at $254 \mathrm{~nm}$. For zearalenone and its cytochrome $\mathrm{P} 450$-generated metabolites, a linear gradient from $40 \% \mathrm{MeOH}$ to $99 \% \mathrm{MeOH}$ in $40 \mathrm{~min}$, constant for $30 \mathrm{~min}$, and back to $40 \% \mathrm{MeOH}$ in 1 min was applied. The total flow rate of the HPLC pumps was $162 \mu \mathrm{L} / \mathrm{min}$ and detection took place using a fluorescence detector $\left(\lambda_{\text {ex }}\right.$ $\left.279 \mathrm{~nm} ; \lambda_{\mathrm{em}} 440 \mathrm{~nm}\right)$. All HPLC separations were carried out on a $150 \times 4.6 \mathrm{~mm}$ i.d. Luna C18(2) column protected with a $2.0 \times 5.0 \mathrm{~mm}$ i.d. C18 guard column (Phenomenex, Amstelveen, The Netherlands). The HPLC column was thermostated at $25^{\circ} \mathrm{C}$.

\section{Results and discussion}

The aim of this research was to combine a recently developed on-line FP detector cell (Kool et al. [20]) with highresolution screening (HRS) technology to develop a sensitive screening platform for measuring the ER $\alpha$ affinities of individual components in mixtures of compounds without incurring interference from autofluorescence at wavelengths below $450 \mathrm{~nm}$. We first synthesized a suitable tracer compound and used this tracer to set up a FP-based ER $\alpha$ binding assay in FP microplate reader format. The optimized assay conditions for the FP microplate reader format were transferred to an on-line bioassay format in FIA mode. In this mode we subsequently optimized the on-line assay conditions and validated them by measuring $\mathrm{IC}_{50}$ values of known estrogenic compounds in both microplate reader format and in FIA mode. We used the optimized conditions in FIA mode to couple the ER $\alpha$ bioassay on-line to a gradient HPLC system. In HPLC mode we measured the ER $\alpha$ bioaffinities of different estrogenic compounds and screened mixtures with five known estrogenic compounds. Finally, we measured the individual $\mathrm{ER} \alpha$ bioaffinities of zearalenone and its metabolites generated off-line by Cyt P450 in HPLC mode.

\section{Synthesis of E2-F}

Synthesis of the fluorescein-labeled derivative E2-F (Fig. 1) was relatively straightforward. The synthetic route described in this paper makes use of readily available chemicals. The yields of intermediate products are relatively high except for the product of the second reaction step, in which compound $\mathbf{2}$ is converted into $\mathbf{3}$. However, the required reactants for this step are not expensive, which makes it possible to perform this step on a large scale. The last and most expensive step involving the coupling of 5-FITC to 7 still gives a yield of $75 \%$ after extraction and purification. Overall, we conclude that this synthetic protocol offers a good alternative to the synthetic scheme described in the literature [7, 19] that is used to produce a fluorescein-labeled E2 derivative. We describe a seven-step synthesis with an overall yield of $12 \%$ compared with an eight-step synthesis in the literature with a total yield of $7 \%$ [19].

To test whether the newly synthesized E2-F had affinity for the $\mathrm{ER} \alpha$, a competitive binding curve for E2-F and ER $\alpha$ LBD was constructed (data not shown) using the coumestrolbased microplate reader assay described by Gurer-Orhan et al. [6]. E2-F was able to displace coumestrol from the $\mathrm{ER} \alpha$ binding site, resulting in an $\mathrm{IC}_{50}$ value of $28.2 \mathrm{nM}$. This value is consistent with $K_{\mathrm{D}}$ values found for similar tracers, which were also in the nanomolar range [7, 19]. Therefore, we concluded that the synthesized E2-F had affinity for the ER $\alpha$ and could be used to further develop a FP-based microplate reader assay.

\section{FP-based microplate reader assay of ER $\alpha$ affinity}

The first step in the optimization of the FP-based microplate reader ER $\alpha$ affinity assay was the investigation of the influence of E2-F tracer concentration upon the FP-based microplate reader assay response of $\mathrm{ER} \alpha$-ligands. To achieve this we compared the FP signal obtained with $0 \%$ 


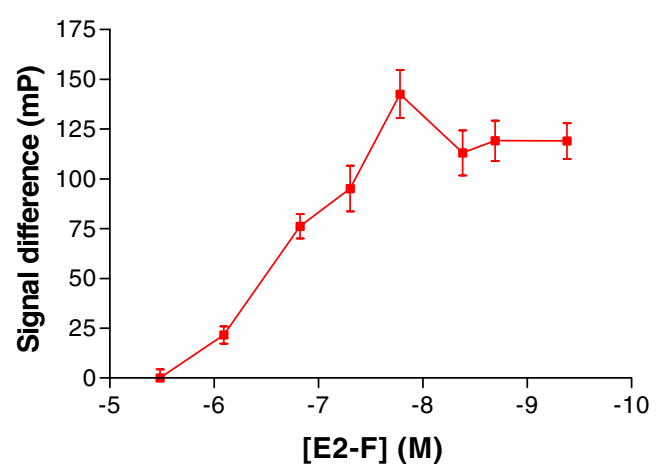

Fig. 3 FP-based microplate reader tracer concentration optimization. Incubations in the presence of ER $\alpha$ ligand E2 $(33.3 \mu \mathrm{M}$; equal to $100 \%$ tracer displacement) were compared with incubations without E2 (equal to $0 \%$ tracer displacement) at decreasing E2-F tracer concentrations

ligand displacement (no E2 present in the incubation) with the FP signal with $100 \%$ ligand displacement $(33.3 \mu \mathrm{M}$ E2 present in the incubation). We also incubated different concentrations of E2-F tracer with a fixed concentration of $\mathrm{ER} \alpha$. The difference in fluorescence polarization $[\Delta \mathrm{FP}$ in millipolarization $(\mathrm{mP})$ ] was plotted against decreasing E2-F concentrations (Fig. 3). From this figure it can be seen that $\Delta \mathrm{FP}$ increases with decreasing tracer $\mathrm{E} 2-\mathrm{F}$ concentrations until it reaches a maximum at $166 \mathrm{nM}$. However, it should also be noted that when the E2-F tracer concentration decreases, the error bars increase, which means that the $\mathrm{S} / \mathrm{N}$ ratios become worse. For the ER $\alpha$-binding assay, we preferred to use a tracer concentration which is not too high, because high tracer concentrations make it necessary to use high concentrations of test compounds as well in order to displace the tracer from the receptor, which results in a decreased assay sensitivity. However, if we use a tracer concentration which is too low, this will also result in unfavorable $\mathrm{S} / \mathrm{N}$ ratios. Based upon our results and the $K_{\mathrm{D}}$ values of 10.4 and $3 \mathrm{nM}$ found by Ohno et al. [19] and Parket et al. [7] respectively for structurally similar fluorescein-labeled E2 derivatives, we decided to use an E2-F tracer concentration of $83.3 \mathrm{nM}$ for further optimization experiments. At this concentration the ER $\alpha$ response was high, which makes it easier to detect the tracerreceptor complex in an on-line assay, with a low $\mathrm{S} / \mathrm{N}$ ratio, and with the concentration in the same range as the $K_{\mathrm{D}}$ value, which makes it possible to determine $\mathrm{IC}_{50}$ values more accurately.

The second step in the optimization process was the investigation of the influence of the detergent Tween 20 and the solvents methanol $(\mathrm{MeOH})$, acetonitrile $(\mathrm{ACN})$ and isopropanol (iPrOH) on assay performance using the conditions as optimized in the previous step. Experiments revealed that Tween 20 was not compatible with the ER $\alpha$ FP assay (data not shown). At very low concentrations $(0.04 \%)$, the presence of Tween 20 in the assay caused a large decrease in $\triangle \mathrm{FP}$ between $\mathrm{E} 2-\mathrm{F}$ bound to $\mathrm{ER} \alpha(0 \%$ displacement; absence of E2) and E2-F displaced by $33.3 \mu \mathrm{M}$ E2 (100\% displacement). Although the addition of Tween 20 can give improved resolution in terms of peak width [25], we decided not to use it due to the large decrease in the difference in polarization. In Fig. 4, the effect of increasing concentrations of $\mathrm{MeOH}, \mathrm{ACN}$ and
Fig. 4 FP-based microplate reader solvent optimization. Incubations in the presence of $\mathrm{ER} \alpha$ ligand E2 (33.3 $\mu \mathrm{M}$; equal to $100 \%$ tracer displacement) were compared with incubations without E2 (equal to $0 \%$ displacement) at increasing $\mathrm{MeOH}$, $\mathrm{ACN}$ and $\mathrm{iPrOH}$ concentrations at an E2-F concentration of $83.3 \mathrm{nM}$

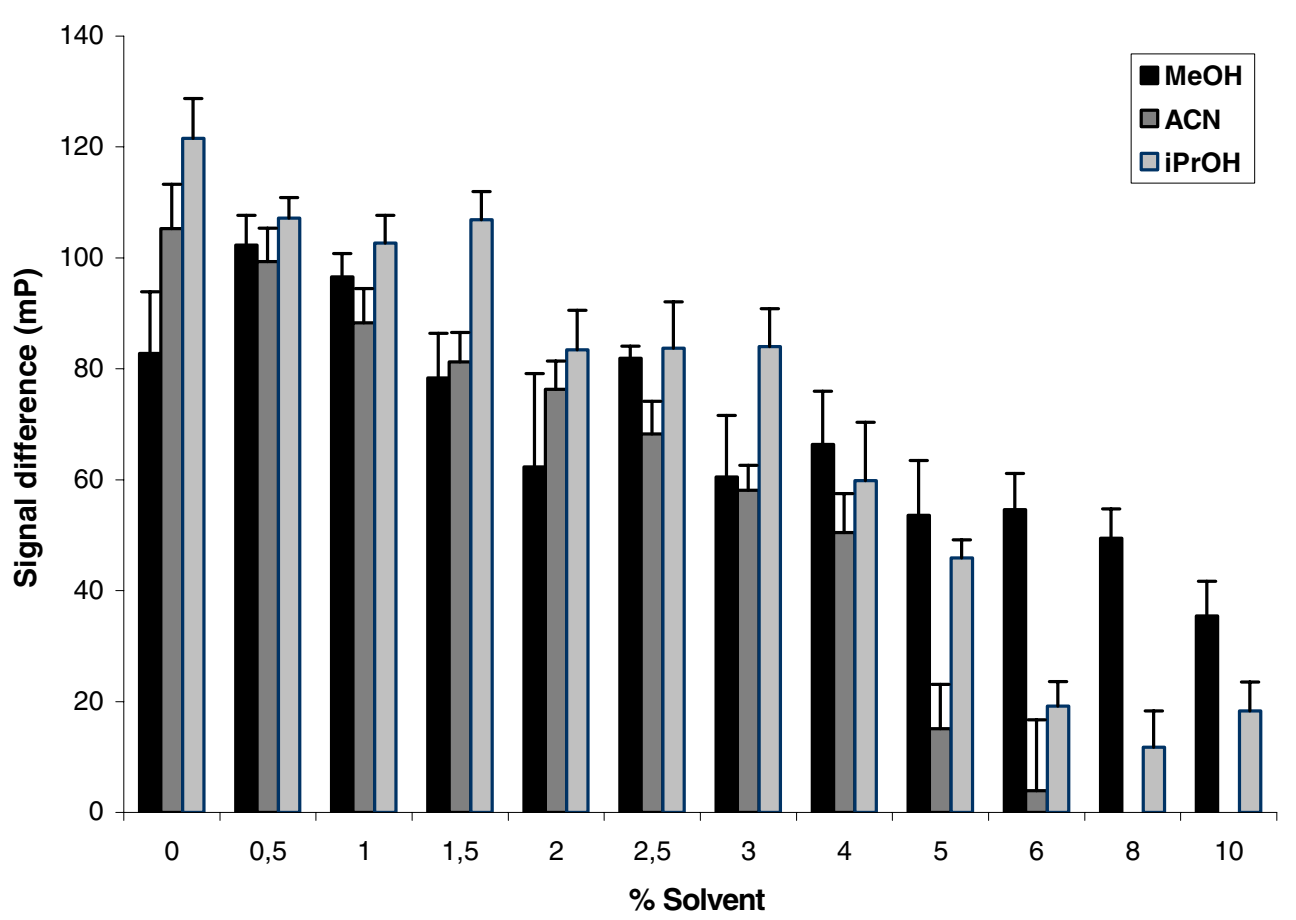




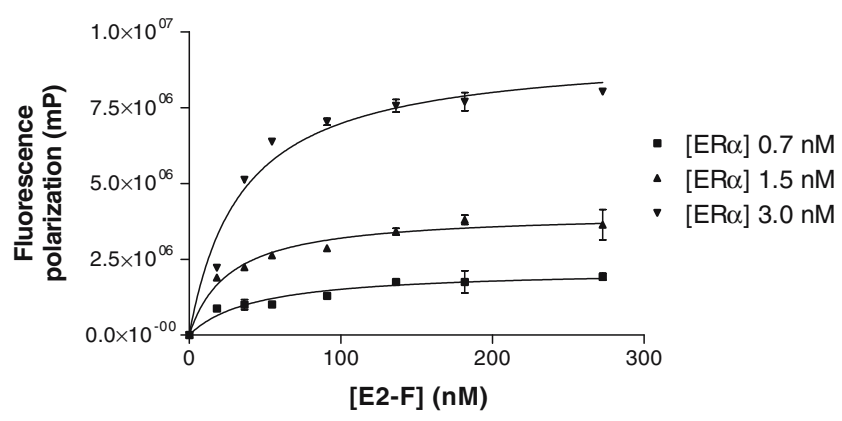

Fig. 5 Determination of $K_{\mathrm{D}}$ and maximum response $\left(R_{\max }\right)$ for E2-F in FIA mode. Different concentrations of E2-F were incubated with three different $\mathrm{ER} \alpha$ concentrations

$\mathrm{iPrOH}$ on $\triangle \mathrm{FP}$ is shown. It can be seen from this figure that $\triangle \mathrm{FP}$ decreases with increasing organic modifier concentrations. $\triangle \mathrm{FP}$ decreased to almost zero for $\mathrm{ACN}$ at the highest concentration. For $\mathrm{MeOH}$ and $\mathrm{iPrOH}$, however, a signal difference between the E2-F bound to $\mathrm{ER} \alpha$ and displaced by E2 could still be observed at the highest modifier concentration. Oosterkamp et al. [10] have stated that denaturation of the estrogen receptor occurs upon prolonged contact with organic solvents such as $\mathrm{MeOH}$ and $\mathrm{ACN}$. It is therefore reasonable to assume that when the organic modifier is present at higher concentrations, the denaturation process for $\mathrm{ER} \alpha \mathrm{LBD}$ increases, which results in smaller fluorescence polarization signal differences.

FP-based ER $\alpha$ receptor affinity detection (RAD) in flow-injection analysis (FIA) mode

The optimized microplate reader assay conditions were transferred to the on-line ER $\alpha$ RAD system in FIA mode (Fig. 2). In this system, compounds introduced by a carrier solution are allowed to bind to the ER $\alpha$ LBD in a first reaction coil, and the E2-F tracer is introduced after this coil. The tracer compound can interact with the unbound receptor in a second reaction coil and detection takes place after the second reaction coil using FP detection. In a FIA setup, carrier solution replaces the gradient HPLC system, thereby allowing the direct injection of compounds and the optimization of on-line assay conditions before final on-line coupling to HPLC. The influence of the ER $\alpha$ LBD and E2$\mathrm{F}$ tracer concentrations and the corresponding excitation and emission wavelengths were investigated in FIA mode in order to optimize the performance of the FP ER $\alpha$ RAD system. The influences of $\mathrm{ACN}$ and $\mathrm{MeOH}$, later used in HPLC mode too, on the FP ER $\alpha$ RAD system performance were also tested in the FIA mode. All measurements were performed in duplicate.

ER $L B D$ and E2-F tracer optimization Different receptor concentrations (ER $\alpha$ LBD) were tested in combination with different tracer concentrations (E2-F) by varying the flows
Table $1 K_{\mathrm{D}}$ and maximum response $\left(R_{\max }\right)$ determination for E2-F in FIA mode

\begin{tabular}{lll}
\hline$[\mathrm{ER} \alpha](\mathrm{nM})$ & $K_{\mathrm{D}}(\mathrm{nM})$ & $R_{\max }(\mathrm{AUC})^{\mathrm{a}}$ \\
\hline 0.7 & $43.6 \pm 12.4$ & $2.17 \times 10^{6}$ \\
1.5 & $26.4 \pm 5.0$ & $4.04 \times 10^{6}$ \\
3.0 & $34.5 \pm 5.3$ & $9.38 \times 10^{6}$
\end{tabular}

${ }^{\mathrm{a}} R_{\max }$ was determined by integrating the decrease in FP signal, and arbitrary units were chosen to display this decrease

of SL-1 (containing $10 \mathrm{nM} \mathrm{ER} \alpha$ in binding buffer) and SL2 (containing $1 \mu \mathrm{M}$ E2-F in binding buffer). The total flow rate was kept constant by introducing a compensating superloop containing only binding buffer. Water was used as carrier solution in order to inject $10 \mu \mathrm{L} 100 \mu \mathrm{M}$ E2 in $50 \% \mathrm{MeOH}$ samples (100\% ligand displacement) in duplicate followed by $10 \mu \mathrm{L}$ injections of $50 \% \mathrm{MeOH}$ ( $0 \%$ displacement) at a flow rate of $250 \mu \mathrm{L} / \mathrm{min}$. The results obtained with these experiments are depicted in Fig. 5. This figure shows that as the E2-F tracer concentration increases the FP signal increases too, until it reaches a maximum. Using the present FIA FP ER $\alpha$ RAD setup, we were able to determine the $K_{\mathrm{D}}$ and maximum response ( $R_{\max }$ ) values for the E2-F tracer compound (Table 1) at different ER $\alpha$ concentrations. The $K_{\mathrm{D}}$ values found were of the same order as observed by Ohno et al. [19] and Parker et al. [7] for an analogous FP tracer compound. It can be seen that $R_{\max }$ increases linearly with higher ER $\alpha$ concentrations, as was expected. Based upon these results, we conclude that the FP ER $\alpha$ RAD in FIA mode worked well, and we continued by investigating the influence of the organic modifier upon the assay performance.

Organic modifier concentration Although we also investigated the influence of $\mathrm{iPrOH}$ upon the ER $\alpha$ bioaffinity assay performance in the FP-based microplate reader format, we decided to evaluate only $\mathrm{MeOH}$ and $\mathrm{ACN}$ in FIA mode based upon the fact that we planned to use only

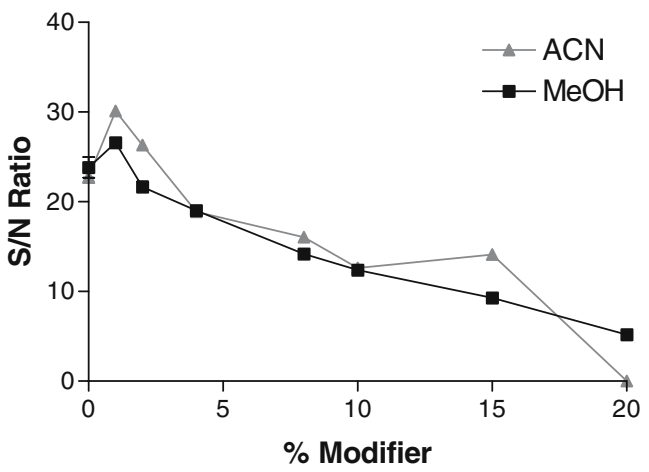

Fig. 6 Effect of $\mathrm{MeOH}$ and $\mathrm{ACN}$ reaction coil concentrations upon the assay performance in FIA mode. The $\mathrm{S} / \mathrm{N}$ ratios of the $\mathrm{E} 2$ injections equalling $100 \%$ tracer displacement are displayed 
Table $2 \mathrm{IC}_{50}$ values determined in FIA mode and in microplate reader assay format

\begin{tabular}{llll}
\hline Compound & FIA mode $\mathrm{IC}_{50}(\mathrm{M} \pm \mathrm{SEM} ; n=3)$ & Microplate setup $\mathrm{IC}_{50}(\mathrm{M} \pm \mathrm{SEM} ; n=3)$ & Literature data $\mathrm{IC}_{50}(\mathrm{M})$ \\
\hline DES & $6.9 \pm 0.3 \times 10^{-9}$ & $6.1 \pm 0.6 \times 10^{-9}$ & $3.5 \times 10^{-9} \mathrm{a}$ \\
Tamoxifen & $1.2 \pm 0.1 \times 10^{-7}$ & $1.3 \pm 0.4 \times 10^{-7}$ & $1.9 \times 10^{-7} \mathrm{a}$ \\
Coumestrol & $1.8 \pm 0.2 \times 10^{-7}$ & $2.5 \pm 0.3 \times 10^{-7}$ & $3.6 \times 10^{-7} \mathrm{~b}$ \\
E2 & $6.7 \pm 0.8 \times 10^{-9}$ & $3.3 \pm 0.3 \times 10^{-9}$ & $5.6 \times 10^{-9} \mathrm{a}$ \\
EE2 & $1.6 \pm 0.2 \times 10^{-9}$ & $3.5 \pm 0.8 \times 10^{-9}$ & $2.3 \times 10^{-9} \mathrm{~b}$
\end{tabular}

$\mathrm{IC}_{50}$ values of five estrogenic compounds towards the $\mathrm{ER} \alpha$, as measured with the RAD system in FIA mode and with the microplate reader assay format. Data from literature ${ }^{\mathrm{a}}[7],{ }^{\mathrm{b}}$ [26] are also shown. DES, diethylstilbestrol; E2, $17 \beta$-estradiol; EE2, $17 \alpha$-ethinyl estradiol

these two solvents in HPLC mode. Different concentrations of $\mathrm{MeOH}$ and $\mathrm{ACN}$ were used as the carrier solution in order to inject $10 \mu \mathrm{L} 100 \mu \mathrm{M}$ E2 ligand in $50 \% \mathrm{MeOH}$ samples (100\% ligand displacement) in duplicate followed by $10 \mu \mathrm{L}$ injections of $50 \% \mathrm{MeOH}(0 \mu \mathrm{M}$ E2 ligand; $0 \%$ displacement) into the system. The $\mathrm{ER} \alpha \mathrm{LBD}$ concentration in the second reaction coil was $2.7 \mathrm{nM}$, the E2-F tracer concentration $110 \mathrm{nM}$ and the total flow rate $300 \mu \mathrm{L} / \mathrm{min}$. Increasing the concentration of $\mathrm{MeOH}$ decreased the $\mathrm{S} / \mathrm{N}$ ratio in FIA mode (Fig. 6). A similar effect was observed with ACN. A possible explanation for this decreasing effect is the partial denaturation of the estrogen receptor due to the presence of high concentrations of organic modifier. Oosterkamp et al. [10] have described this phenomenon during the optimization of the $\operatorname{ER} \alpha$ coumestrol-based RAD system when a decrease in response was observed upon the contact of the ER $\alpha$ with organic solvents such as $\mathrm{MeOH}$ and ACN. One advantage of a higher organic modifier concentration is that higher flow rates can be used in HPLC gradients, which may result in shorter analysis times and higher resolutions. Another advantage is that high concentrations of organic modifier prevent lipohilic compounds from adsorbing to the walls of the reaction coils and other tubing, which may increase resolution. Based upon our results during FP FIA setup, we concluded that both $\mathrm{MeOH}$ and ACN might be used in the on-line gradient HPLC system.

Excitation and emission wavelengths When the excitation and emission wavelengths were varied, the optimal FP signal responses in FIA mode were obtained at an excitation wavelength of $498 \mathrm{~nm}$ and an emission wavelength

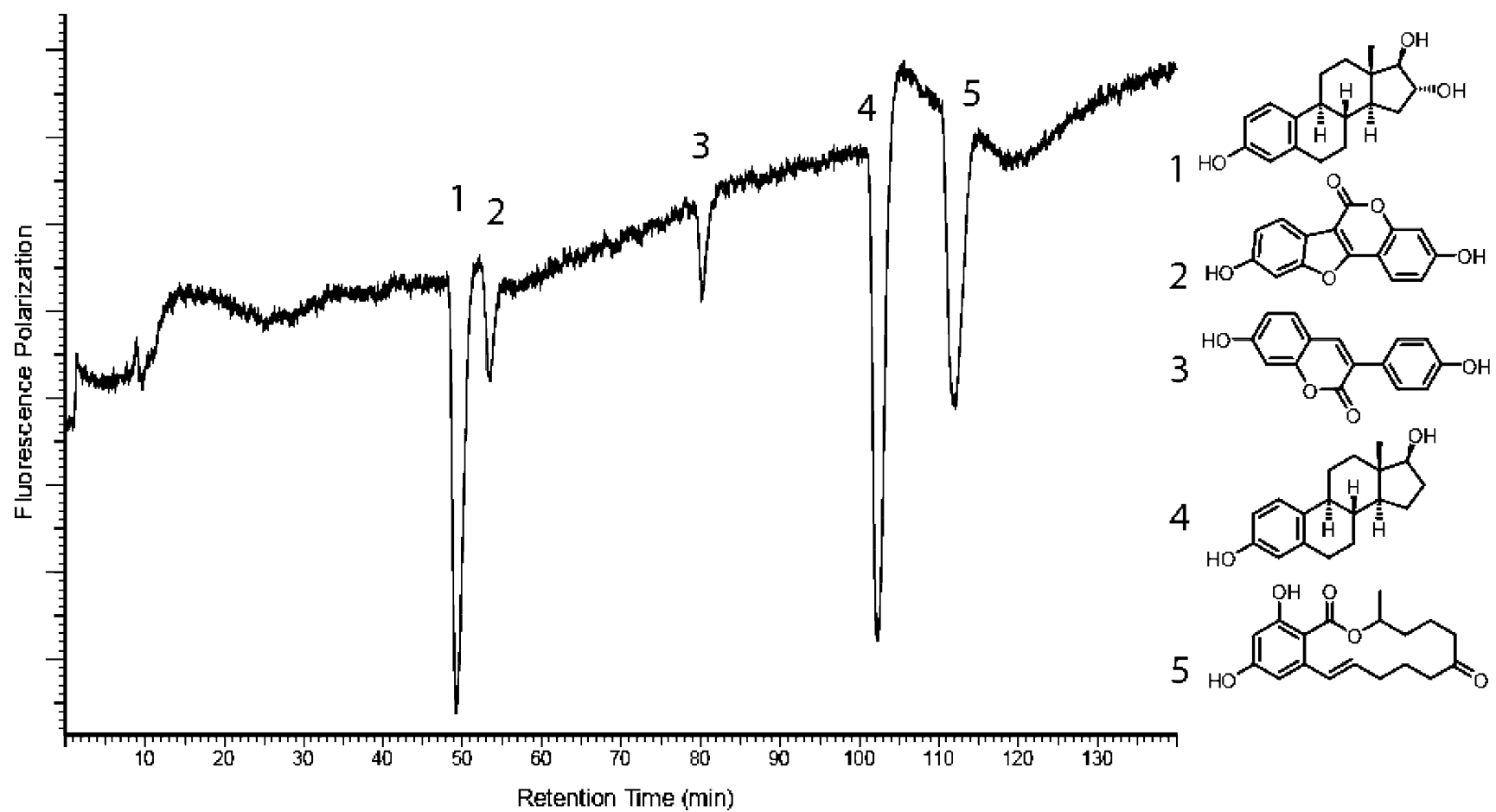

Fig. 7 ER $\alpha$ FP RAD trace of a mixture of five estrogenic compounds injected into the ER $\alpha$ FP RAD HPLC system (injected compounds are as follows: estriol (1) $[3.75 \mathrm{nmol} ; 49.5 \mathrm{~min}]$, coumestrol (2)
[3.75 nmol; $53.7 \mathrm{~min}$ ], coumarol (3) [37.5 nmol; $80.4 \mathrm{~min}], 17 \beta-$ estradiol (4) $[3.75 \mathrm{nmol} ; 102.8 \mathrm{~min}]$ and zearalenone (5) $[12.5 \mathrm{nmol}$; $112.5 \mathrm{~min}]$ 
of $522 \mathrm{~nm}$ (data not shown). These wavelengths were therefore used to further optimize the on-line FP system in FIA mode.

Competitive receptor binding curves To validate the ER $\alpha$ FP RAD system, competitive binding curves for five known estrogenic test compounds-DES, E2, EE2, tamoxifen and coumestrol-were constructed using the FP-based microplate reader assay, and these values were compared with the $\mathrm{IC}_{50}$ values obtained using the ER $\alpha$ FP setup in FIA mode. The ER $\alpha$ LBD concentration was $1.6 \mathrm{nM}$ and the E2-F tracer concentration was $80 \mathrm{nM}$ for the microplate reader assay. In FIA mode, the ER $\alpha$ LBD concentration in the second reaction coil was $2.7 \mathrm{nM}$ and the E2-F concentration was $110 \mathrm{nM}$. All five test compounds displayed sigmoidal concentration-response curves during both the microplate reader setup and in FIA mode, and from these curves we were able to determine the $\mathrm{IC}_{50}$ values (Table 2). The values found in the two different setups were similar for each individual compound and in agreement with values obtained from the literature $[7,26]$. We thus demonstrated that the FP-based microplate reader assay and the ER $\alpha$ FP setup in FIA mode could be employed to determine the $\mathrm{IC}_{50}$ values of a wide range of typical ER $\alpha$-binding ligands accurately. The next step in the process of developing the HRS platform was to couple the FIA ER $\alpha$ FP system to a gradient HPLC system on-line.

FP-based ER $\alpha$ receptor affinity detection coupled on-line to HPLC

Following assay optimization in the microplate reader and FIA modes, the ER $\alpha$ FP RAD assay was coupled on-line to

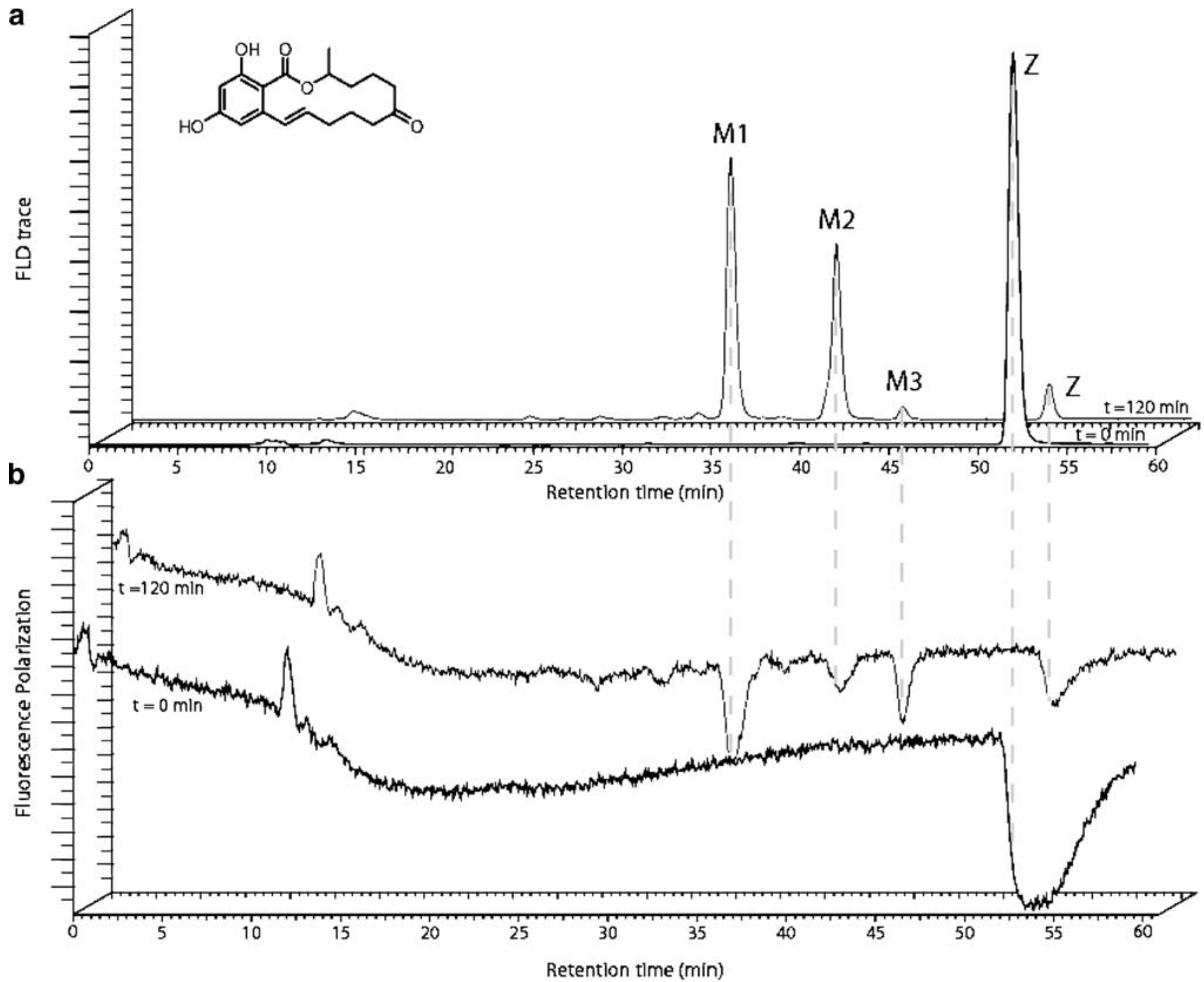

Fig. 8a-b a HPLC FLD chromatograms of zearalenone (Z) incubated for 0 and 120 min with PB-induced rat liver microsomes. M1, M2 and M3 are metabolites formed during the 120-min incubation period. b
The corresponding ER $\alpha$ FP affinity traces. The structure of zearalenone is depicted in the figure 
gradient HPLC. In this HRS setup the flow eluting from an HPLC column was coupled directly to the FP RAD system, which enables compound separation prior to the screening of individually eluting compounds for their ER $\alpha$ affinities. This allowed us to screen for compounds with ER $\alpha$ affinities in mixtures. To test the performance of the on-line HRS FP ER $\alpha$ system, different concentrations of the phytoestrogen coumestrol were injected first. A negative peak in the $\mathrm{ER} \alpha$ bioaffinity trace was observed at a retention time of $40 \mathrm{~min}$, which is the exact time when coumestrol eluted from the HPLC column (data not shown). As expected, the negative bioaffinity peaks became larger upon injections of higher concentrations of coumestrol. The highest negative peaks were observed when all of the E2-F was displaced by coumestrol. Higher concentrations of coumestrol only caused more tailing of the bioaffinity peaks. These measurements illustrate that the ER $\alpha$ bioaffinity of the phytoestrogen coumestrol could be measured sensitively and efficiently with the new E2-F based HRS ER $\alpha$ FP system, which is not possible due to the occurrence of autofluorescence using the coumestrol-based ER $\alpha$ HRS system developed by Oosterkamp et al. [10].

Representative superimposed chromatograms of different concentrations of a mixture of five known estrogenic compounds-coumestrol, coumarol, estriol, 17 $\beta$-estradiol and zearalenone-are depicted in Fig. 7. Although some baseline drift in time is observed over two hours, it is quite possible to detect the ER $\alpha$ bioaffinities of all five individual peaks in the mixture. The explanation for the baseline drift is most likely that the post-column makeup HPLC gradient does not totally compensate for the effect of variations in the organic modifier concentration. The FP ER $\alpha$ RAD system is sensitive to changes in the organic modifier concentration, as shown during FIA optimization, and this can lead to baseline drifts.

To illustrate another application of the on-line HRS ER $\alpha$ FP system, metabolites of the phytoestrogen zearalenone, which were anticipated to show affinity for the ER $\alpha$, were analyzed in the present FP-based HRS ER $\alpha$ system. For this purpose, zearalenone was metabolized by phenobarbital (PB)induced rat liver microsomes in an off-line fashion, followed by analysis with the FP-based HRS system. The results are depicted in Fig. 8. The UV trace of the $t=0$ min incubation shows that zearalenone $(\mathrm{Z})$ elutes at $51.4 \mathrm{~min}$. The corresponding bioaffinity trace shows that zearalenone has affinity for ER $\alpha$. The FLD trace of the $t=120 \mathrm{~min}$ incubation shows that zearalenone is metabolized by rat liver microsomes into at least three major metabolites (M1: 33.5, M2: 39.5 and M3: $43.2 \mathrm{~min}$ ). The corresponding bioaffinity trace demonstrates that all three major metabolites (M1-3) have affinity for ER $\alpha$. LC/MS measurements were performed to identify the three major metabolites. M1 had a molecular ion at an $\mathrm{m} / \mathrm{z}$ value of 333 , which likely corresponds to a monohydroxylated zearalenone metabolite. M2 had a mo- lecular ion at an $\mathrm{m} / z$ value of 317 , which is the exact same $\mathrm{m} / \mathrm{z}$ value as that of zearalenone itself. This can be explained by the relocation of the double carbon-carbon bond next to the aromatic ring. However, more research must be performed to confirm this. M3 had a molecular ion at an $\mathrm{m} / \mathrm{z}$ value of 319 , which corresponds well to the $\mathrm{m} / \mathrm{z}$ value of the zearalenone metabolite zearalenol described in the literature [27]. The metabolism of zearalenone in vitro by rat liver microsomes has been described very recently by Pfeiffer et al. [28], and they confirm the findings of M1 and M3. The present Cyt P450 metabolism experiment illustrates that it is possible to screen metabolic mixtures of phytoestrogenic compounds for ER $\alpha$ affinity using the present FPbased HRS ER $\alpha$ setup. However, no further structural elucidation of the zearalenone metabolites has been performed, because the goal of the present experiment was only to show that the on-line FP HRS ER $\alpha$ assay can be used to screen for parent compounds and metabolites of phytoestrogens with $\mathrm{ER} \alpha$ affinity.

We conclude that we succeeded in developing, for the first time, an on-line FP-based HRS platform to screen for ER $\alpha$ affinity using the novel on-line FP detector cell recently described in a FIA mode by Kool et al. [20]. The sensitivity of the FP-based HRS platform is comparable to that of the coumestrol-based HRS platform, and no interference from fluorescence was observed at wavelengths below $450 \mathrm{~nm}$. The novel on-line FP detector cell can in principle be applied to other HPLC-based bioaffinity assays which require FP detection. The present HRS ER $\alpha$ FP system offers a novel technology for investigating the metabolic profiles of drugs and other compounds such as phytoestrogens which cannot be measured by the coumestrol-based HRS system due to the occurrence of autofluorescence from the test compounds.

Acknowledgements The ER $\alpha$ LBD-expressing Escherichia coli cells were a kind gift from Dr. Marc Ruff and Dr. Dino Moras. We thank Dr. Maikel Wijtmans and Ing. Elwin Janssen for their assistance with the synthesis of E2-F and Dr. Marola van Lipzig for synthesizing coumarol. We would especially like to thank D.J. van Iperen and K. van Altena for the construction of the on-line FP detector cell.

Open Access This article is distributed under the terms of the Creative Commons Attribution Noncommercial License which permits any noncommercial use, distribution, and reproduction in any medium, provided the original author(s) and source are credited.

\section{References}

1. Schulte-Oehlmann U, Albanis T, Allera A, Bachmann J, Berntsson P, Beresford N, Carnevali DC, Ciceri F, Dagnac T, Falandysz J, Galassi S, Hala D, Janer G, Jeannot R, Jobling S, King I, 
Klingmuller D, Kloas W, Kusk KO, Levada R, Lo S, Lutz I, Oehlmann J, Oredsson S, Porte C, Rand-Weaver M, Sakkas V, Sugni M, Tyler C, van Aerle R, van Ballegoy C, Wollenberger L (2006) Environ Health Perspect 114(Suppl 1):98-100

2. Kool J, Ramautar R, van Liempd SM, Beckman J, de Kanter FJ, Meerman JH, Schenk T, Irth H, Commandeur JN, Vermeulen NP (2006) J Med Chem 49:3287-3292

3. Ropero AB, Alonso-Magdalena P, Ripoll C, Fuentes E, Nadal A (2006) J Steroid Biochem Mol Biol 102:163-169

4. McDonnell DP (2005) Clin Cancer Res 11:871s-877s

5. Usami M, Mitsunaga K, Ohno Y (2002) J Steroid Biochem Mol Biol 81:47-55

6. Gurer-Orhan H, Kool J, Vermeulen NPE, Meerman JHN (2005) Int J Environ Anal Chem 85:149-161

7. Parker GJ, Law TL, Lenoch FJ, Bolger RE (2000) J Biomol Screen 5:77-88

8. Oosterkamp AJ, Irth H, Villaverde Herraiz MT, Tjaden UR, van der Greef J (1997) J Chromatogr A 787:27-35

9. Przyjazny A, Hentz NG, Bachas LG (1993) J Chromatogr A 654:79-86

10. Oosterkamp AJ, Villaverde Herraiz MT, Irth H, Tjaden UR, van der Greef J (1996) Anal Chem 68:1201-1206

11. Ingkaninan $\mathrm{K}$, Hazekamp A, de Best CM, Irth H, Tjaden UR, van der Heijden R, van der Greef J, Verpoorte R (2000) J Nat Prod 63:803806

12. Schenk T, Appels NM, van Elswijk DA, Irth H, Tjaden UR, van der Greef J (2003) Anal Biochem 316:118-126

13. de Boer AR, Letzel T, van Elswijk DA, Lingeman H, Niessen WM, Irth H (2004) Anal Chem 76:3155-3161
14. Kool J, van Liempd SM, van Rossum H, van Elswijk DA, Irth H, Commandeur JN, Vermeulen NP (2007) Drug Metab Dispos 35:640-648

15. Schobel U, Frenay M, van Elswijk DA, McAndrews JM, Long KR, Olson LM, Bobzin SC, Irth H (2001) J Biomol Screen 6:291-303

16. van Liempd SM, Kool J, Niessen WM, van Elswijk DE, Irth H, Vermeulen NP (2006) Drug Metab Dispos 34:1640-1649

17. Maragos CM, Jolley ME, Plattner RD, Nasir MS (2001) J Agric Food Chem 49:596-602

18. Trinquet E, Mathis G (2006) Mol Biosyst 2:381-387

19. Ohno K, Fukushima T, Santa T, Waizumi N, Tokuyama H, Maeda M, Imai K (2002) Anal Chem 74:4391-4396

20. Kool J, Van Marle A, Hulscher S, Selman M, Van Iperen DJ, Van Altena K, Gillard M, Bakker RA, Irth H, Leurs R, Vermeulen NP (2007) J Biomol Screen 12:1074-1083

21. Buu-Hoi NGPH, Ekert B, Royer R (1954) J Org Chem 19:1548-1552

22. Rooseboom M, Commandeur JN, Floor GC, Rettie AE, Vermeulen NP (2001) Chem Res Toxicol 14:127-134

23. Eiler S, Gangloff M, Duclaud S, Moras D, Ruff M (2001) Protein Expr Purif 22:165-173

24. van Lipzig MM, ter Laak AM, Jongejan A, Vermeulen NP, Wamelink M, Geerke D, Meerman JH (2004) J Med Chem 47:1018-1030

25. Kool J, van Liempd SM, Ramautar R, Schenk T, Meerman JH, Irth H, Commandeur JN, Vermeulen NP (2005) J Biomol Screen 10:427-436

26. Matthews J, Celius T, Halgren R, Zacharewski T (2000) J Steroid Biochem Mol Biol 74:223-234

27. Zollner P, Jodlbauer J, Kleinova M, Kahlbacher H, Kuhn T, Hochsteiner W, Lindner W (2002) J Agric Food Chem 50:2494-2501

28. Pfeiffer E, Heyting A, Metzler M (2007) Mol Nutr Food Res $51: 867-871$ 